\title{
DEL TRÁNSITO PRESIDENCIAL EN LA SALA 2. DEL TCFA Y DE SU REFLEJO EN LA SUPERACIÓN DE SU DISPARATADA SENTENCIA WEISS, DE 5 DE MAYO DE 2020
}

\section{Of the presidential transition in the 2nd Chamber of the CTFA and its reflection in overcoming its absurd Weiss ruling of 5 May 2020}

\author{
ANTONIO LÓPEZ CASTILLO \\ Universidad Autónoma de Madrid \\ antonio.lopez@uam.es
}

\begin{abstract}
Cómo citar/Citation
López Castillo, A. (2021)

Del tránsito presidencial en la Sala 2. ${ }^{a}$ del TCFA y de su reflejo en la superación de su disparatada sentencia Weiss, de 5 de mayo de 2020

Revista Española de Derecho Constitucional, 122, 333-366 doi: https://doi.org/10.18042/cepc/redc.122.10
\end{abstract}

Resumen

En la sentencia Weiss/PSPP la Sala 2. a del TCFA ha llevado la aplicación del control de ultra vires al extremo, hasta entonces inédito, de desautorizar, por arbitraria e infundada, la interpretación prejudicial del TJUE y, con ello, su inaplicación al caso; mediante un ejercicio exorbitante de interpretación alternativa del DUE (su alternativa interpretación competencial del principio de proporcionalidad confiere a su decisión un tinte arbitrista) al que se anuda la prescripción de tareas a los órganos políticos (que mediatamente apelan a la propia UE), de hacer y de no hacer. La reacción ante tal desatención de la divisoria jurisdiccional ha llevado, de inmediato, a la Sala $2 .^{\mathrm{a}}$, de presidencia entrante, a modular el sentido y alcance de su remanente jurisdicción de control (no solo) de ultra vires, soltando el lastre-Weiss, en la 
pretensión de recuperar la congruencia iuseuropea de su función como juez de la aplicabilidad del DUE y de recuperar su prestigio como referente.

\title{
Palabras clave
}

Tribunal Constitucional (Sala 2a); Tribunal de Justicia de la UE; Cuestión prejudicial; límites a la aplicabilidad del DUE; control de ultra vires; identidad constitucional; responsabilidad por la integración; legitimación en queja por inconstitucionalidad; el TCFA como juez del derecho europeo y nacional integrado.

\begin{abstract}
In the Weiss/PSPP judgment, the 2nd Chamber of the TCFA took the application of ultra vires control to the hither to unprecedented extreme of disallowing, as arbitrary and unfounded, the preliminary ruling of the CJEU and thus its inapplicability to the case; by means of an exorbitant exercise of alternative interpretation of the TEU (its alternative interpretation of the principle of proportionality gives its decision an arbitrary bias) to which is attached the prescription of tasks for the political bodies (which, in the medium term, appeal to the EU itself) to do and not to do. The reaction to such disregard for the jurisdictional dividing line has immediately led the 2nd Chamber, with its incoming presidency, to modulate the meaning and scope of its remaining jurisdiction of (not only) ultra vires control; releasing the Weiss ballast, in an attempt to recover the ius European congruence of its function as judge of the applicability of the EU Law and to recover its prestige as a point of reference.
\end{abstract}

\section{Keywords}

Constitutional Court (2nd Chamber); Court of Justice of the EU; preliminary ruling; limits to the applicability of the EU law; ultra vires control; constitutional identity; responsibility for integration; standing to complain of unconstitutionality; the GCC as a judge of EU law and integrated national law. 


\section{SUMARIO}

I. CONSIDERACIONES INTRODUCTORIAS: PRESENTACIÓN Y PLANTEAMIENTO. II. DE LA PERSISTENTE DISCREPANCIA ACERCA DE LA COMPLEJA DINÁMICA (ECONÓMICA) DE FONDO Y DE SU PRETENDIDO (MEJOR) ENCAJE NORMATIVO... III. ... AL ESPERPÉNTICO DISPARATE HERMENÉUTICO DE LA SALA 2." (DE PRESIDENCIA SALIENTE) SOBRE UN FONDO DOCTRINAL (CONCEPTISTA) DE PRETENDIDA CONSECUENCIA CON LA CONSTITUTIVA DIVISORIA JURISDICCIONAL IUSEUROPEA: 1. ¿Qué se ha hecho de la divisoria jurisdiccional? 2. Y (sin rodeos, tras el fogonazo soberanista de Maastricht) ya ¡todo en ti fue democracia!... 3. ... ¡Hasta disparatar, sin medida! IV. A MODO DE CONCLUSIÓN, O SOBRE CÓMO RECUPERAR EL SENTIDO DE LA MARCHA, SIN PERJUICIO DE UNA REMANENTE RESERVA DE JURISDICCIÓN DE (HIPOTÉTICO) CONTROL DE LÍMITES A LA APLICABILIDAD DEL DUE. BIBLIOGRAFÍA.

\section{CONSIDERACIONES INTRODUCTORIAS: PRESENTACIÓN Y PLANTEAMIENTO}

a. La sentencia Weiss. En el resumen de mi comentario a la sentencia OMT de la Sala 2.a del TCFA, de 21 de junio de 2016, se decía que la firme predisposición del TJUE al diálogo, pese a la singularidad procesal y sustantiva del caso, se había recibido «de un modo equívoco y ambivalente, condicionando unos criterios cuya observancia se deja[ba] bajo vigilancia de los órganos constitucionales responsables por la integración», dando así a entender que la "disputa» continuaría.

Y, en adenda se anunciaba que, mediante Auto de 18 de julio de 2017, la Sala volvía a interpelar al TJUE en el marco de procedimientos pendientes de resolución en queja por inconstitucionalidad (as. 2BvR 859/15, e. a.), en relación ahora con el milmillonario programa de compras del sector público, PSPP, «insistiendo en el posible desconocimiento de la interdicción de financiamiento monetario del presupuesto y en un exceso competencial del mandato en materia de política monetaria imputable al BCE».

Y sin dejar de señalar «la aparente pretensión de modular el ampuloso "derecho a la democracia" con otras referencias, tales como "derecho a la auto determinación democrática”, y la confirmación de la cautelosa orientación pro futuro de un condicionamiento interpretativo, si hipotético respecto del 
inactivado programa OMT, operativo en relación con otros programas, como el cuestionado PSPP», se dejaba allí para «otra ocasión el comentario de este nuevo episodio de comunicación prejudicial»" ${ }^{1}$.

Esa ocasión ha llegado con la sentencia Weiss (o PSPP), de 5 de mayo de 2020, una desafiante reacción de la Sala 2. ${ }^{a}$ (de presidencia saliente) ante la contenida sentencia prejudicial del TJUE, de 11 de diciembre de 2018, que, en su formación de Gran Sala, había intentado dar respuesta a las inquietudes formuladas desde Karlsruhe.

Pues bien, todo parece indicar que, mediante su sentencia Weiss, la Sala 2. a del TCFA ha querido festejar su fin de curso presidencial ${ }^{2}$. Y lo ha hecho de un modo estrepitoso y, por lo demás, disparatado. En abierta discrepancia con las interpretaciones prejudiciales que, no sin esfuerzo, sentara el TJUE, en su sentencia homónima. Esta resolución, dictada en respuesta al segundo auto prejudicial de la Sala $2 .^{a^{3}}$ ha sido frontalmente desautorizada, de un modo desconsiderado e inconsistente, por lo demás, con los criterios hermenéuticos que, en su acerba crítica al TJUE, la propia Sala invoca. Contrariando así esa expectativa de cooperativo desempeño de la jurisdicción del DUE que, por definición, integra la práctica de la prejudicialidad iuseuropea.

$\mathrm{Y}$ lejos de contentarse con matizaciones y salvedades, como en su sentencia $O M T$, en la presente ocasión, la Sala 2. ${ }^{\text {a }}$ (de ponencia huberiana) sostiene abiertamente, contra el criterio prejudicial expreso por el TJUE, que la decisión inicial del BCE y las que, en su aplicación, se sucedieron se habían de considerar adoptadas ultra vires, por su patente desborde respecto de lo establecido mediante los arts. 119 y 127, TFUE, y 17 y siguientes del Estatuto del SEBC.

Como se ha de exponer luego, en detalle, al proceder así, la Sala 2. ${ }^{a}$ desconoce la presupuesta divisoria funcional en la jurisdicción relativa al DUE, declarando por sí misma el desajuste con sus bases jurídicas de las decisiones relativas a la puesta en marcha y sucesiva aplicación del programa PSPP, y al constatar por su propia autoridad una insuperable falta de motivación y

Cit. de López Castillo (2017a: 342 y 376).

2 La actual presidencia de la Sala 2.a está en manos de la magistrada Doris König, vicepresidenta del TCFA, desde el pasado 22 de junio de 2020 (véase Deutscher Bundestag, 19. Wahlperiode, Drucks. 19/19993, 16-6-2020, Wahlvorschlag; Plenarprotokoll 19/166, Deutscher Bundestag, Stenographischer Bericht, 166. Sitzung, Berlin, den 18. Juni 2020; ese día, la candidata propuesta obtuvo una mayoría de 500 diputados, contra 97 noes y 78 abstenciones).

3 Vid. referencia en Pressemitteilung Nr. 70/2017, de 15 de agosto de 2017; a propósito de esta segunda cuestión prejudicial me permito remitir a López Castillo (2017b). 
fundamentación por parte del TJUE. Al que se considera incurso en ultra vires. Por su desmayada práctica de control del potencial efecto económico de ese controvertido programa, al no haber procedido a verificar si el BCE pudo tenerlo en cuenta, sopesarlo y ponderarlo, en observancia del principio de proporcionalidad. Y sin la documentación acreditativa de esa debida ponderación — se dice - no le habría sido posible al TJUE una efectiva práctica de control jurisdiccional del mandato del BCE. Y dicho esto, la Sala 2. a, lejos de quedarse en la crítica al desempeño jurisdiccional del TJUE, se arroga la responsabilidad de declarar vulnerado el art. 5.1. 2 y 4 TUE, por decisiones (relativas al programa PSPP) que considera adoptadas a descubierto de las competencias que, en materia de política monetaria, asisten al BCE.

Reactivaría así la Sala 2. (de presidencia saliente) una subsidiaria jurisdicción de interpretación del derecho primario (o, más precisamente, de remanente control del derecho derivado a la luz de una restricta interpretación constitucional de conformidad del derecho primario). Y ello se justifica en la inoperatividad de un control (acerca de las exigencias derivadas del principio de proporcionalidad y del restricto mandato monetario del SEBC) en una cuestionable autorrestricción del TJUE en el desempeño de su función jurisdiccional de interpretación y control del DUE. Su deferencia ante la discrecionalidad decisoria del BCE y la desatención de sus excesos habrían llevado al TJUE — prosigue diciendo la Sala 2. a — a una arbitraria dejación de la función jurisdiccional que, ex art. 19.1 y 2 TUE, se le encomienda. Y acto seguido, la Sala 2. a se desliga ya de la obligada decisión interpretativa del TJUE ${ }^{4}$.

Descarta, en cambio, la Sala 2. ${ }^{a}$, enjuiciar el grado de cumplimiento de su responsabilidad por la integración por parte del Gobierno y de la Dieta federales considerando que, sin examinar en detalle las actuaciones del BCE, no les habría sido posible concluir nada sobre su ajuste al principio de proporcionalidad, ni acerca de la compatibilidad del programa PSPP con el art. 127.1

4 Es bien sabido, ya desde el Auto del TJCE de 5 de marzo de 1986, as. C-69/85, que un órgano judicial cuestionante en vía prejudicial, si bien puede volver a exponer al TJUE nuevos elementos de apreciación a fin de que se pueda tornar sobre la interpretación relativa a la cuestión planteada, no puede hacer de esa hipótesis una especie de recurso de reconsideración de la sentencia prejudicial ya emitida, como no cabe tampoco sustituir la interpretación prejudicial del TJUE por una propia, ya sea tras el pronunciamiento expreso del TJUE (véase STC 26/2014, Melloni), ya sea sin haber dado ocasión a que se pronuncie por elusión de la cooperativa relación prejudicial (véase STCFA 2015, Haftbefehl II), al margen del derecho vigente, y de la divisoria funcional sobre la que descansa la integración iuseuropea (véase ATJUE de 5 de marzo de 1986, as. c-69/85, Wünsche Handelgesellschaft, párr. 15). 
TUE5. Con todo - les advierte la Sala 2. a —, en lo sucesivo, esa responsabilidad por la integración les habría de llevar a contrarrestar sucesivas actuaciones del programa PSPP, en el marco de sus respectivas atribuciones y con los medios a su alcance, velando por la observancia del programa de integración y tratando de suprimir cuantas medidas pudieran desbordarlo y de limitar, en lo posible, su efecto interno; intentado, en suma, que el BCE se conduzca conforme al principio de proporcionalidad y que el SEBC se atenga a las atribuciones propias de su mandato.

Sentado que ningún órgano constitucional, autoridad o tribunal alemán ha de participar en la puesta en marcha, aplicación, ejecución u operacionali-

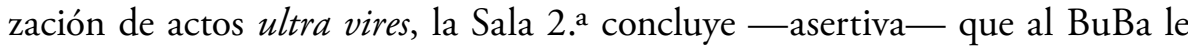
estaría vedado participar en la puesta en práctica y ejecución de las decisiones en cuestión si, en un plazo transitorio, de, como máximo, tres meses, no se clarificase, mediante una nueva decisión de su Consejo de gobierno, que los objetivos perseguidos por el programa PSPP guardaban relación con los efectos causados en la política económica y fiscal. Y, dado el alcance de su participación (26\%) en el programa, se le obliga a procurar una paulatina vuelta atrás en los compromisos de compra a largo plazo de bonos estatales.

Por otra parte, en atención a toda una serie de precisiones, declara la Sala 2. ${ }^{\text {a }}$ que aún no se constataba una vulneración del art. $123.1 \mathrm{TFUE}^{6} . \mathrm{Y}$, a propósito de la pretendida quiebra de la identidad constitucional, sub specie responsabilidad presupuestaria de la Dieta federal, concluía diciendo que eso no pasaba de ser una simple hipótesis ajena al estado de la cuestión, pues ni el derecho primario ha previsto tal cosa ni el acotado ámbito del art. 79.3 LF se vería alterado en tanto que no se modifiquen las reglas de distribución del riesgo.

b. Las reacciones a la sentencia Weiss. La contundencia inusitada del pronunciamiento ha provocado reacciones sin fin en el espacio constitucional

5 La pretensión de someter a control constitucional, en vía de ejecución de sentencia, la observancia de esa responsabilidad por parte de Gobierno y Dieta federales ha sido desatendida por la Sala 2. ${ }^{\text {a }}$ TCFA, mediante resolución de inadmisión, de 29 de abril de 2021, 2 BvR 1651/15 y 2 BvR 2006/15, por infundada, pues, sobre excederse los límites propios de un mandato de ejecución, ex art. $35 B V \operatorname{rer} G G$, se pretende un nuevo examen de fondo que la Sala descarta (por no apreciarse inacción ni advertirse inadecuación manifiesta alguna en lo actuado).

6 Así, expresamente, por la limitación del volumen de compras, la forma agregada en que se dan a conocer, el límite máximo del $3 \%$ del papel, la correspondencia con la clave de capital de los bancos centrales, la adquisición solo de títulos de corporaciones con acceso a los mercados o, en fin, la posible reventa en el mercado, cumplido el objetivo de inflación (véase n. ${ }^{\circ}$ marg. 217). 
europeo; en medios institucionales de la Unión Europea (desde la advertencia de la Comisión acerca de la posible apertura de un expediente tendente a la declaración de incumplimiento al singular comunicado de prensa n.o 58/20 del TJUE o a la previa nota de prensa del Banco Central Europeo) ${ }^{7}$, tanto como en otros Estados miembros (tal y como evidencian la consulta de la hemeroteca y el repaso a los blogs especializados en aquellos días del pandémico mes de mayo en España) ${ }^{8}$, y, desde luego, también en la propia Alemania,

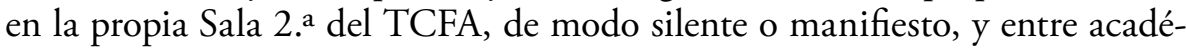
micos y miembros de la magistratura ${ }^{9}$.

Ciertamente, las discrepancias interpretativas del TCFA con el TJUE venían de lejos; no nacen con la ya agotada presidencia Vosskuhle ${ }^{10}$. Pero, lo cierto es que, andando el tiempo, la Sala 2. a enredada ya de antiguo en encadenamientos conceptistas, de pretendido vuelo dogmático, cobró un renovado impulso durante el mandato de esa voluntariosa presidencia. No sin resistencias, explícitas o no, en el interior de la Sala ${ }^{11}$.

7 TJUE, Comunicado de prensa a raíz de la sentencia, de 8 de mayo de 2020 (cp200058es.pdf, en www.curia.europa.eu); Nota de prensa, 5 de mayo de 2020, «El BCE toma nota de la sentencia del Tribunal Constitucional Federal alemán y mantiene su pleno compromiso de acuerdo con su mandato" (presbce2020_80.pdf, en www.bde.es; véase la declaración de Von der Leyen de 10 de mayo de 2020 en www.ec.europa.eu).

8 A título de ejemplo, por su inmediatez, pueden mencionarse, por lo que a España se refiere, tanto las notas «La sentencia... ¿y ahora qué?» (Lozano Cutanda, 2020) y «El Tribunal constitucional alemán y su "fuego amigo" sobre el TJUE y el BCE» (Mangas Martín, 2020) como la tribuna «Exit Karlsruhe», de Cruz Villalón, en El País, de 13 de mayo de 2020, que habla de un «segundo día negro del año para el gran proyecto de integración política que es la Unión Europea».

9 Por su inmediatez, cabe destacar la puntillosa crítica de Mayer (2020) y las ajustadas apreciaciones de Meier-Beck (2020).

10 El mandato del entonces presidente del TCFA finalizaba el 6 de mayo de 2020. Le vino a sustituir, tras su elección mediante decisión unánime por parte del Bundesrat, el 15 de mayo, Stephan Harbarth, que, ya desde noviembre de 2018, presidía la Sala 1. a del TCFA (véaseBundesrat Drucksache 253/20, 14. Mai 20, y Plenarprotokoll 989, BRat Stenographischer Bericht, 989. Sitzung, Berlin, 15. Mai 2020).

11 Véanse VV. PP de Roberts y Lübbe-Wolf, en Auto prejudicial de 14 de enero de 2014, y la silente oposición (en consonancia con el VP a la STCFA de 13 de febrero de

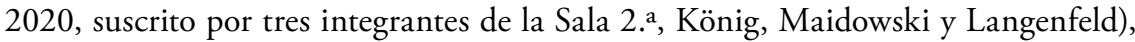
que resulta de la adopción de esta controvertida sentencia Weiss, e. a. o PSPP por mayoría de siete votos contra uno (y, si bien no se dice, todo apunta a que esa sorda 
Y, ante la coyuntura desafortunada en la que vino a pronunciarse (en plena devastación económica y social como consecuencia del cierre de fronteras y severa ralentización, si no práctica parálisis, de la producción al hilo de diversas modalidades de confinamiento por la pandemia), un día antes de la fecha de cumplimiento del mandato del presidente saliente, la Sala se vería en la (penosa) obligación de clarificar una obviedad, que las medidas financieras adoptadas por la UE y por el BCE en relación con la crisis del coronavirus no eran objeto de su decisión.

Que tras lo que se sostiene en la sentencia Weiss hay una firme voluntad de manifestar una discrepancia doctrinal parece algo claro. Que, al arrogarse esa especie de compensatoria función de control jurisdiccional del DUE, la Sala 2 . $^{\text {a }}$ incurre ya en un disparate conceptual, es justamente lo que se ha de poner de manifiesto en lo que sigue. Considerando la suma de desafiantes asertos en el contexto de su jurisprudencia iuseuropea (III). Pero, antes de eso, se impone un apunte sintético sobre la controvertida dinamicidad que singulariza un agregado proceso de configuración de la UEM que a duras penas encaja en su normativo marco convencional (II). Finalmente, a modo de conclusión, se tratarán de esbozar los perfiles de lo que, más que parecer, ya es la constatación de un viraje de la Sala 2.a, de renovada presidencia, al efecto de modular el desencuentro con el TJUE, superando esa destemplada altisonancia que en la sentencia Weiss, e. $a$. ha alcanzado su pico más saliente (IV).

\section{DE LA PERSISTENTE DISCREPANCIA ACERCA DE LA COMPLEJA DINÁMICA (ECONÓMICA) DE FONDO Y DE SU PRETENDIDO (MEJOR) ENCAJE NORMATIVO...}

Es de todo punto evidente que del tenor de la disciplina convencional a la praxis aplicativa de la política monetaria por parte del BEC y el SEBC media un vasto trecho que la sucesiva aplicación de las llamadas medidas no convencionales ha contribuido, sin duda, a ensanchar.

Es bien sabido, asimismo, que, desde la primera oportunidad disponible, la Sala 2. a del TCFA, mediante su constitutiva sentencia Maastricht, propuso una condicionada interpretación de la programada gradualidad de la Unión económica y monetaria (UEM), al hilo de la relectura del fundamento constitucional y alcance del compromiso integracionista europeo de aquella Alemania de novado estatuto de soberanía. Y es en ese contexto de

oposición se habría de imputar a la actual vicepresidenta del TCFA, y presidenta de la Sala 2. ${ }^{\mathrm{a}}$, Doris König). 
reafirmación de la soberanía política y constitucional de Alemania en el que se ha de entender su afirmación acerca de la potencial reversibilidad del proceso, pretendidamente inexorable, de asunción de compromisos en el sucesivo tracto de la prefigurada UEM y su condicionada precomprensión, como comunidad de estabilidad.

A partir de ahí, con la sucesión de crisis que marcan la transición de la Europa de entre siglos, esa latencia de conflicto hermenéutico, a caballo del tenor de disposiciones convencionales de restricto alcance (como la excluyente de deuda mutualizada, ex art. 125 TFUE) y de una lata praxis aplicativa, ha evidenciado la acuciante necesidad de avanzar en el sentido de una concorde interpretación del texto, en contexto, tratando de apuntalar una revirada lectura del compromiso iuseuropeo de compleción de la UEM, como si hacer de la necesidad virtud fuera el empeño.

La experiencia de estos años de crisis superpuestas ha puesto de relieve las insuficiencias de esa mera agregación que tradicionalmente ha guiado el repentismo iuseuropeo; así, por ejemplo, al hilo de la pretendida resolución de la crisis financiera, mediante adopción de decisiones políticas, expresivas de una disciplina mixta, entre iuseuropea e iusinternacional, propiciando que de un problema coyuntural de la banca privada, al hilo de un incesante flujo de capital del centro a la periferia, que llegaría a lastrar a las entidades bancarias prestadoras, resultara finalmente una ingente deuda pública de los Estados periféricos con los Estados signatarios de los compromisos de líneas de crédito altamente condicionadas - como préstamos bilaterales concertados o mediante dotación temporal de un mecanismo y un fondo europeos de estabilidad financiera, MEEF y FEEF, o, ex art. 136.3 TFUE $^{12}$, mediante una estructura permanente (MEDE) - ${ }^{13}$.

Pues bien, no es un secreto que esa insatisfactoria gestión política de los nocivos efectos de la crisis financiera y económica llegó a potenciar el riesgo en sendos Estados miembros y para la propia UEM. Y tanto o más evidente es

12 Véase, a propósito del MEDE y de su soporte primario, la singular Sentencia TJUE, Pleno, de 27 de noviembre de 2012 (singular por diversos conceptos, por la formación del TJUE que la dicta, por su particular objeto de control, una decisión (2011/199) modificadora, mediante procedimiento simplificado de reforma, del TFUE, y aun por su referencia a la temporizada ratificación por parte de los EE. MM. del acuerdo constitutivo del MEDE, estando entonces aún pendiente la entrada en vigor de aquella decisión).

13 Así, sucesivamente, en relación con Grecia, 2010; Irlanda, 2010; Portugal y Grecia, 2011, y, en fin, Chipre, 2013, y Grecia, 2015, tras una inicial asistencia a España, 2012 . 
que ese contexto de crítico condicionamiento financiero es lo que explica la salida a la palestra del BCE mediante su política de compra de deuda pública (comenzando ya en la primavera de 2010 con la compra de deuda pública de Grecia, Irlanda y Portugal, y, sucesivamente, de Italia y de España). Con el anuncio, ya en el segundo semestre de 2012, de un programa de operaciones monetarias irrestrictas (Outright Monetary Transactions, OMT), para la compra potencialmente ilimitada de deuda pública en los mercados secundarios, con el objetivo confeso de contribuir a la efectividad de sus decisiones monetarias, en vista de que la especulación en los mercados, inmersos en un ambiente altamente inestable, estaría generando unos diferenciales excesivos en los tipos de interés que los Estados miembros de la eurozona asumían al emitir deuda pública.

Y aunque ese singular anuncio produjera su efecto sin que el BCE hubiera de pasar a la acción, la Sala 2. ${ }^{a}$ del TCFA (bajo presidencia de Vosskuhle), no quiso dejar pasar la ocasión para poner de manifiesto su pretendida ortodoxia alternativa a propósito de las atribuciones del BCE en materia de política monetaria, mediante una especie de condicionada oferta hermenéutica de restricto encaje constitucional (Auto de 15 de enero de 2014), criticada con tino ya en las conclusiones ( 15 de enero de 2015) del AG Cruz Villalón, en línea con los (dos) jueces discrepantes de aquella resolución.

Entretanto, en espera de la respuesta prejudicial del TJUE (que llegaría pasados cinco meses $)^{14}$, el BCE pondría en marcha, en marzo de 2015, un nuevo mecanismo de intervención, el llamado programa de compras del sector público (Public Sector Purchase Programme, PSPP), sucesivamente prorrogado, que ha propiciado la compra de un montante considerable de deuda pública en la eurozona (contrarrestando así, en alguna medida, los agudos efectos de la contraproducente conjunción de políticas arbitristas de recorte del gasto público y de la persistente presión de los mercados de deuda pública ${ }^{15}$.

A mayor abundamiento, en respuesta a la emergencia sanitaria (covid19), al margen de la suspensión de la disciplina de la competencia, del régimen de limitación de las ayudas de Estado y de la aplicación de la cláusula de salvaguardia del pacto de estabilidad y crecimiento, se ha soslayado la interdicción de actuación del $\mathrm{BCE}$ como comprador de último recurso de deuda pública. Lo que se ha traducido en un programa de compras de emergencia en la

14 Mediante Sentencia TJUE, Gran Sala, de 16 de junio de 2015, as. C-62/14, Gauweiler e. a.

15 Así, al inicio del segundo semestre de 2020, en el marco del programa PSPP, el BCE había adquirido ya un montante de 2,24 billones de euros; y, por lo que a la deuda española respecta, sumaba ya un acumulado de 281396 millones de euros. 
pandemia (Pandemic emergency purchase programme, PEPP), al efecto de adquirir bonos del tesoro de los Estados miembros de la eurozona, sin límite y sin correspondencia con el porcentaje de la clave de participación por país en el capital del BCE, atendiendo solo a sus necesidades de financiación, mediante compras asimétricas de deuda pública en los mercados secundarios, en un montante considerable, sin dejar de mirar al obligado referente de inflación $(2 \%)^{16}$.

Por lo demás, ante las consecuencias económicas derivadas de la reactivación de la pandemia, el Consejo de gobierno del $\mathrm{BCE}$ ha procedido a recalibrar sus instrumentos de política monetaria, acordando, entre otros extremos, "[mantener sin variación] el tipo de interés de las operaciones principales de financiación y los tipos de interés de la facilidad marginal de crédito y de la facilidad de depósito [...] en el $0,00 \%, 0,25 \%$ y $-0,50 \%$, respectivamente», «incrementar la dotación del programa de compras de emergencia frente a la pandemia (PEPP) en $500 \mathrm{~mm}$ de euros hasta un total de $1850 \mathrm{~mm}$ de euros» $\mathrm{y}$ «amplia[r] el horizonte de las compras netas en el marco del PEPP al menos hasta final de marzo de 2022»; aclarando que, en todo caso, se «efectuará[n] compras netas hasta que [se] considere que la fase de crisis del coronavirus ha terminado», se "seguir[á] reinvirtiendo el principal de los valores adquiridos en el marco del PEPP que vayan venciendo al menos hasta el final de 2023",

16 Véase la Decisión (UE) 2020/440, BCE, de 24 de marzo de 2020, sobre un programa temporal de compras de emergencia en caso de pandemia (DOUE L 91, 25 de marzo de 2020, 1-4); el montante de 1350000 millones de euros previsto hasta junio de 2021 se ha ampliado en 500000 millones de euros adicionales, hasta marzo de 2022, en la reunión de 10 de diciembre de 2020 (información accesible desde www.ecb. europa.eu); en este punto, es preciso aclarar que, a finales de noviembre pasado, las compras de deuda pública espańola (solo) alcanzan los 77128 millones, frente a los 111810 millones de deuda francesa, los 118169 millones de deuda italiana o los 160619 millones de deuda alemana.

Por lo demás, a propósito de los 750000 millones de euros (hasta 390000 no reembolsables), del instrumento europeo de recuperación Unión Europea Próxima Generación/European Union Next Generation, que financiar mediante una emisión comunitaria de deuda a largo plazo (amortizable hasta 2058), y de los respectivos planes nacionales de recuperación y resiliencia - España puede. Plan de recuperación, transformación y resiliencia, Presidencia del Gobierno, Madrid, octubre de 2020 (07102020_PlanRecuperacion.pdf), accesible desde www.lamoncloa.gob.es, véanse, por otros, Menéndez Menéndez, 2020: 15-90; Real Decreto Ley 36/2020, de 30 de diciembre, por el que se aprueban medidas urgentes para la modernización de la Administración pública y para la ejecución del Plan de recuperación, transformación y resiliencia, en $B O E, 341$, de 31 de diciembre de 2020, pp. 126733-93-. 
y que, en todo caso, «la futura extinción de la cartera PEPP se gestionará de forma que se eviten interferencias con la orientación adecuada de la política monetaria» ${ }^{17}$.

Ahora bien, que el Consejo de Gobierno del BCE aclare que «sigue estando preparado para ajustar todos sus instrumentos según proceda, a fin de asegurar que la inflación avance hacia su objetivo de forma sostenida, en línea con su compromiso de simetría ${ }^{18}$, siendo como es algo positivo, no supone alternativa alguna a la necesaria reforma atemperada de la disciplina convencional de la UEM. Y, al efecto de superar la persistente tensión, entre latente y patente, a la hora de interpretar el sentido y alcance del mandato monetario del BCE, al margen de lo fundado o infundado de las discrepancias cruzadas, entre tribunales (TJUE y TCFA, en este caso), sin duda, se impone recomponer unas asimetrías iuscomunitarias, de la deuda al crédito, sin las que, a medio plazo, la proyectada compleción de la UEM seguramente se resienta. Pues, empecinarse en monetizar la deuda pública, sin proceder a una refleja comunitarización del crédito, al tiempo que solivianta a esos querulantes

Asimismo, ese Consejo de gobierno ha decidido, en síntesis, reajustar las condiciones de la tercera serie de operaciones de financiación a plazo más largo con objetivo específico (TLTRO III), ampliando en doce meses, hasta junio de 2022, el período durante el que se aplicarán condiciones considerablemente más favorables (tres operaciones adicionales se efectuarán también entre junio y diciembre de 2021), así como aumentar el importe total que las entidades de contrapartida podrán obtener mediante operaciones TLTRO III, desde el 50 hasta el $55 \%$ de sus préstamos computables; y ampliar hasta junio de 2022 la duración de las medidas de flexibilización de los criterios de admisión de activos de garantía que adoptó el 7 y el 22 de abril de 2020; ofrecer otras cuatro operaciones de financiación a plazo más largo de emergencia frente a la pandemia (PELTRO) en 2021, que seguirán proporcionando un apoyo de liquidez efectivo; dar continuidad a las compras netas en el marco del programa de compras de activos (APP), a un ritmo mensual de $20 \mathrm{~mm}$ de euros, reinvirtiendo íntegramente el principal de los valores adquiridos en el marco del APP que vayan venciendo durante un período prolongado tras la fecha en la que comiencen a subir los tipos de interés oficiales del BCE y, en todo caso, durante el tiempo que sea necesario para mantener unas condiciones de liquidez favorables y un amplio grado de acomodación monetaria; ampliando hasta marzo de 2022 la facilidad repo del Eurosistema para bancos centrales (EUREP) y todas las líneas swap y repo de carácter temporal con bancos centrales no pertenecientes a la zona del euro, $y$, en fin, seguir ejecutando sus operaciones periódicas de FI. Asimismo, mediante subastas a tipo de interés FIM con adjudicación plena en las condiciones vigentes mientras sea necesario.

18 Véase la correspondiente referencia, en lengua española, en www.ecb.europa.eu. 
soberanistas que en la Europa de entre siglos han acudido incansables a Karlsruhe, no conduce sino al despeńadero a la eurozona, por no decir a la propia Unión Europea como comunidad política in fier ${ }^{19}$.

Pero, entre tanto, mientras que ese horizonte, entre virtuoso y necesario, no se alcance a perfilar, toca volver a la gestación de la política monetaria del BCE y a su control jurisdiccional por parte del TJUE, en su caso; pero no necesariamente insistiendo en la traza esperpéntica que dibuja la sentencia Weiss, por parte del TCFA (u otros de sus correspondientes).

\section{III. ... AL ESPERPÉNTICO DISPARATE HERMENÉUTICO DE LA SALA 2. (DE PRESIDENCIA SALIENTE) SOBRE UN FONDO DOCTRINAL (CONCEPTISTA) DE PRETENDIDA CONSECUENCIA CON LA CONSTITUTIVA DIVISORIA JURISDICCIONAL IUSEUROPEA}

\section{1. ¿QUÉ SE HA HECHO DE LA DIVISORIA JURISDICCIONAL?}

En este punto inicial, es preciso reconocer que una cosa, del todo sostenible, es que entre TJUE y TCFA (u otro TC o TS) se llegue a poner de manifiesto una cierta discrepancia, no necesariamente infundada, a propósito de la interpretación del sentido de los títulos atributivos de competencia en materia monetaria y del delimitado alcance de su aplicación, mediante una sucesiva adopción de decisiones y de medidas, no convencionales, al efecto de limitar los riesgos de distorsión de la transmisión de la comunitaria política monetaria, en un contexto, además, de crisis superpuestas, de ida y vuelta de lo monetario a lo económico. $\mathrm{Y}$, otra cosa, bien distinta y cuestionable, es que, al hilo de esa legítima discrepancia, se trate de ignorar o se desconozca la constitutiva divisoria funcional de la jurisdicción del DUE, desatendiendo la disciplina común, mediante desautorización de la jurisdicción del TJUE. Y eso es, precisamente, lo que ha hecho la Sala $2 .^{a}$, de presidencia saliente, mediante afirmación unilateral de autoridad arrogada en el ejercicio de una especie de reserva (permanente) de jurisdicción de control de la aplicabilidad del DUE.

19 Pues, como bien se ha dicho, «[e]stá en juego nuestro futuro», y, sin predeterminar su concreta forma política (o «constitución», por decirlo a la manera del maestro Rubio Llorente, 2013), ya sea «[f]ederal, confederal o descentralizada, Europa necesita más solidaridad [esa] materia de la que están hechas las comunidades políticas» (Menéndez Menéndez, 2020: 81). 
Bien es sabido que, al hilo de la salvaguarda de los límites de la LF y, en particular, de los esenciales de los derechos fundamentales, en su evolutiva doctrina Solange (y, en todo caso, desde su resolución de 2000, relativa al asunto Plátanos), la Sala $2 .{ }^{\text {a }}$ había llegado a la práctica renuncia a una reserva de jurisdicción semejante. Pero, acaso lo sea menos - y conviene, por ello, recordarlo- que, a partir de su definitoria sentencia Maastricht, mediante una decidida reformulación del sentido y alcance del novado (y de inicio ignorado) fundamento constitucional de la integración europea, comenzaría a hilar ya la Sala $2 .^{\text {a }}$ una concatenada secuencia terminológica de pretendido porte conceptista, que, desde entonces, ha encarnado en un rosario de resoluciones, entre cuyos hitos descuella, como fulgurante cuenta, la sentencia Weiss $^{20}$.

Que ya desde el pasado siglo la cuestión del control último de la interpretación autorizada de la divisoria competencial ha llevado a propuestas diversas, buscando alguna alternativa al TJUE, es cosa también conocida, aunque a veces no lo parezca ${ }^{21}$. Y en ese sentido, el planteamiento reciente, a modo de antídoto para Weiss, de una alternativa pretendidamente salvífica, mediante la configuración de una jurisdicción de conflictos, de integración mixta, a partir de los jueces del TJUE y de tribunales constitucionales $(\mathrm{o} / \mathrm{y}$ supremos) de los Estados miembros, por más que se formule ello con rigor ${ }^{22}$, tiene un punto de ocurrencia (siquiera sea porque da la impresión de tomarse en serio lo que no es sino un disparate jurisprudencial que, si no se revirtiese por la vía del entendimiento ${ }^{23}$, seguramente requeriría de una firme corrección y sanción) apenas cohonestable con la lógica federativa del proceso de integración ${ }^{24}$.

20 Otra resolución reciente de la Sala 2. ${ }^{\mathrm{a}}$ que, por su manifiesto exceso de jurisdicción (del que expresamente disintieron tres de sus integrantes en VP), se ha de referir aquí es su Sentencia de 13 de febrero de 2020, as. 2BvR 739/17 (accesible desde www. bundesverfassungsgericht.de).

21 Véase, por otros, Stein (1986: 619 y ss.); asimismo, en perspectiva comparada y a propósito ya de la constitutiva sentencia Maastricht del TCFA, Mayer (2000: passim).

22 Véase, en particular, Weiler y Sarmiento Ramírez (2020).

23 En esa línea, se inserta la reciente reformulación del sentido y alcance de sus tópicos relativos al pretendido control de aplicabilidad del DUE (véase referencia a la reciente sentencia de la Sala 2. ${ }^{\text {, }}$ de renovada presidencia, de 1 de diciembre de 2020, en IV), que viene precedido de una publicitada reunión de trabajo con una delegación del TJUE en la sede del TCFA (nota de prensa n.o 91/2020, de 20 de octubre).

24 En esta línea de preocupada advertencia se han manifestado voces autorizadas en el espacio iuseuropeo, como Vassilios Skouris y Angelika Nussberger, antiguos presidentes del TJUE y del TEDH; véase referencia a sus intervenciones en el debate sobre 
En todo caso, antes de pasar al desglose de los términos manifiestos del planteamiento conceptista que, en esta ocasión, ha llevado a la Sala 2. a a negar de plano la interpretación prejudicial sentada por el TJUE, en respuesta a sus diversas cuestiones, con el exclusivo soporte de su pretendida autoridad hermenéutica (3.), conviene apuntar al origen de unas formulaciones de principio que, sobre su aparente continuidad, pronto fueron objeto de un profundo replanteamiento de fondo y de forma. Pues, en el tracto de su jurisprudencia iuseuropea, la Sala 2. ${ }^{a}$ ha recorrido un largo trecho que va desde su inicial reivindicación de una hipotética reserva de jurisdicción de control como una especie de garantía última de los elementos esenciales, $v$. gr., iusfundamentales, de la LF (en una línea similar a la que, no sin inconsecuencias argumentales, se sigue aferrando el TC español), hasta su arrogada jurisdicción (discontinua, pero permanente) de reserva (recurrente) para la salvaguarda (puntual, e incluso preventiva) de un comprensivo principio democrático que, en su confluente dimensión de subjetiva pretensión ius fundamentale simile y como objetiva faceta principal, potencialmente tiende a abarcar el orden constitucional (todo), en la medida en que la cuestión para examen se acierte a poner en relación, porque directamente se anude o porque indirectamente se conecte, con esa enfatizada soberanía nacional de Alemania que, entre siglos, comenzara a sonar como ruido (democrático) de fondo (2.).

\section{Y (SIN RODEOS, TRAS EL FOGONAZO SOBERANISTA DE MAASTRICHT) YA ¡TODO EN TI FUE DEMOCRACIA!...}

Se tratará aquí de repasar, al margen de la (forzada) paráfrasis de un conocido verso de Neruda ${ }^{25}$, uno de esos lugares comunes por los que, con frecuencia, se transita sin prestar demasiada atención, las sentencias Solange.

En la primera de ellas, en el marco procesal del llamado control concreto de normas, no sin una controversia dentro de la Sala 2. ${ }^{\text {a }}$ manifiesta en un VP

la sentencia Weiss de la Sala 2. a del TCFA (Wie kommen BVerfG und EuGH wieder in Dialog?), tal y como lo cuenta Rath, 2020. Por lo demás, entre otros muchos comentaristas, Ludwig (2020) y Nettesheim (2020).

En esta línea de desatención con el TJUE, se inscribe -ya en pruebas- una controvertida decisión del TC de Polonia (ref. no P7/20), de 14 de julio de 2021.

25 "Todo en ti fue naufragio» (de «La canción desesperada», en Veinte poemas de amor y una canción desesperada, de Pablo Neruda, 1924), divulgado por la voz intergeneracional de Paco Ibáñez (Paco Ibáñez interpreta a Pablo Neruda, editado en el sello Paula, de Ariola Records, actual Sony Music). 
suscrito por tres de sus ocho integrantes, se reivindicaba una subsidiaria jurisdicción de control de constitucionalidad del derecho nacional derivado del derecho comunitario, previamente interpretado por el TJUE, siempre que, y en la medida en que, el órgano jurisdiccional cuestionante lo considerase inaplicable por su colisión con alguno de los derechos fundamentales de la LF; «en tanto que el proceso de integración de la Comunidad no estuviese tan desarrollado como para que también el derecho comunitario dispusiera de un catálogo de derechos fundamentales acordado por un Parlamento y en vigor $»^{26}$.

Esa hipotética jurisdicción de control indirecto del derecho comunitario se ponía, así, en relación con la inexistencia de una comunidad (política) sujeta a un catálogo de derechos fundamentales elaborado y aprobado por un Parlamento (en abierto debate entonces acerca de superación de aquella Cámara de delegados de sendos Parlamentos nacionales por un Parlamento democráticamente electo de representantes de los pueblos de los Estados miembros - lo que, tras la entrada en vigor del Acta electoral europea, en 1976, se hizo realidad ya a mediados de 1979—). Y acaso eso («a la vista, por ejemplo, de los acontecimientos políticos y jurídicos que se han producido entre tanto en el ámbito europeo») ilumine el sentido de su indefinición (quizá) al dejar entonces en duda la continuidad de una reserva de jurisdicción, si practicable, centrada en el control de constitucionalidad de la ley alemana de prestación de consentimiento del Tratado ${ }^{27}$.

Examinada en su integridad, la segunda sentencia Solange $e^{28}$ muestra algo más que un ensayo de acomodación, mediante inversión de su conocida reserva, al estado de la cuestión de los derechos fundamentales en la jurisprudencia del TJUE — «[...] en tanto que [...] la jurisprudencia del TJUE

26 Sentencia de 29 de mayo de 1974, BvL 52/71, Solange-Beschluss, en BVerfGE 37, 271 y ss. - en su voto discrepante, los jueces Rupp, Hirsch y Wand subrayaron ya, con apoyo en la Sala 1. a, tanto la divisoria jurisdiccional como, a propósito de inadmitidas quejas por inconstitucionalidad contra derecho comunitario derivado, la interdicción de una extensiva interpretación analógica por el TCFA para autoatribuirse competencias de control al margen de lo dispuesto en su propia ley de procedimiento; véase en II. 3. a) y b) del referido VP-.

27 Como es evidente, ese pronunciamiento de la Sala 2. ${ }^{\text {a }}$, mediante su Sentencia de 25 de julio de 1979, 2BvL 6/77, Vielleicht-Beschluss, en BVerfGE 52, 187 y ss. (en B.3, n. ${ }^{\circ}$ marg. 38), se produjo contando ya con un Parlamento europeo democráticamente legitimado por su elección directa (al margen de que, hasta 2002, mediante la correspondiente revisión del AEE, fuera posible compatibilizar ese mandato con un mandato representativo nacional).

28 Sentencia de 22 de octubre de 1986, 2 BvR 197/83, en BVerfGE 73, y ss. 
garantice, en general, una efectiva tutela de derechos fundamentales frente a [...] las Comunidades europeas, que sea equiparable, en lo esencial, al estándar ius fundamental que, de modo incondicionado (contenido esencial de los DDFF), brinda la LF [...] el TCFA no volvería a ejercitar su jurisdicción sobre la aplicabilidad de derecho comunitario derivado [...]»-

Pues, al tiempo que se reformulaba esa reserva "en tanto que» ${ }^{29}$, en Solange II se soslayaba un aspecto que había sido medular en Solange I, el de su condicionalidad a la espera de un catálogo vigente de DD. FF. elaborado por un Parlamento (electo). Y eso que, entonces (a finales de 1986), el PE se afanaba ya, mediada su segunda legislatura como Cámara electa de representantes de los pueblos de los Estados miembros, en el intento de formalizar, por remisión o mediante articulación, una segura sujeción de las actuaciones comunitarias a compartidos estándares de iusfundamentalidad ${ }^{30}$.

La Sala 2. ${ }^{\text {a }}$ ponía ya un particular empeño en la caracterización de su eventual objeto de control directo, en esa ley de prestación del consentimiento, $y$, con ello, en el fundamento constitucional de unas atribuciones restrictas y de limitado alcance conforme al mandato de aplicación que, como fuente nacional de legitimación democrática, esa ley de autorización instrumentalmente integra. Y en esa línea se pasaría a precisar, sin solución de continuidad, que la observancia del «mandato de aplicación» demandaría su delimitación hermenéutica a fin de que los actos comunitarios que pudieran dictarse en exceso (ausbrechende Akte) no disfrutaran de la cobertura legitimadora que solo los adoptados en el marco del programa de integración autorizado por esa ley podían pretender tener ${ }^{31}$. Y de ahí, de su concepción de un programa de integración, como contenido posible, hermenéuticamente delimitable, del mandato de aplicación ínsito en la ley de autorización expresiva de la

29 Una reserva de jurisdicción que, de modo muy singular, reaparecería en la sentencia Maastricht (1993), antes de su reducción a la jíbara, al llevar su hipotética reactivación a la extremada hipótesis de una caída sistemática de los estándares iusfundamentales o de falencia estructural en la prestación de su efectiva tutela, en su conocida sentencia Plátanos, de 7 de junio de 2000, 2 BvL 1/97.

30 Véase, a. e., proyecto Spinelli, 1984 (referente de ulteriores concreciones, en 1994), o la resolución relativa a una declaración de derechos, 1989, etc.

31 Véase la Sentencia de 8 de abril de 1987, Kloppenburg (BVerfGE 75, 223, ss.), más conocida por sancionar, por primera vez, una omisión de planteamiento de cuestión prejudicial (por parte del Tribunal federal de lo financiero), mediante interpretación integrativa de la cláusula de garantía constitucional, ius fundamentale simile, de acceso al juez legal, ex art. 101.1, 2. a frase, LF, que por la compleción de esta secuencia que va de la fundamentación nacional democrática a la salvaguarda constitucional de un mandato de aplicación de alcance determinable. 
legitimación democrática que contribuye al soporte y sustento del proceso de integración, a la configuración jurisdiccional de una adicional variante de reserva de control constitucional de aplicabilidad en Alemania del derecho

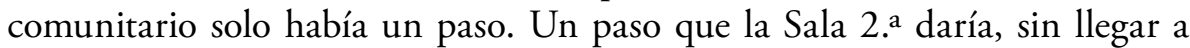
cuestionar, formalmente, que su objeto de enjuiciamiento directo fuera la ley de autorización, dando curso, así, a su conocida reserva de jurisdicción de control de ultra vires.

$\mathrm{Y}$ a esa ganancia de jurisdicción de control indirecto de la aplicabilidad en Alemania del DUE sumaría muy pronto la Sala 2. a del TCFA un hallazgo de dimensiones antes desconocidas. Mediante la caracterización de un título de legitimación para acceder al TCFA, en queja por inconstitucionalidad, como un invocable ius fundamentale simile en defensa de la democracia (nacional) de la que cada ciudadano podría hacer valer su alícuota parte.

Así, con base en la vertiente sustantiva del art. 38.1, frase, LF, mediante su constitutiva sentencia Maastricht, se abría un cauce, por no decir un atajo, procesal que, en su evolutiva desfiguración ulterior ${ }^{32}$, ha llevado al TCFA a la práctica arrogación, por defecto, de una subsidiaria, intermitente, pero permanente, jurisdicción de control de aplicabilidad del DUE contra el expreso criterio hermenéutico sentado por el TJUE; en su caso, previo planteamiento de cuestión prejudicial, en la medida en que se considere indirectamente vulnerada la LF, por desconocimiento o merma de contenidos intangibles que, por definición o conexidad, entendiera la Sala $2 .^{a}$ que guardan relación con la democracia, como derecho o/y principio fundamental.

En esa determinante decisión Maastricht (dicho sea al modo schmittiano), en el puntilloso detalle del argumentario de su ponencia (kirchhoffiana), elaborada — según se ha dicho- al servicio del renovado estatuto iusinternacional de la Alemania recién unificada, se hilaban condicionamientos rotundos (así, al margen de la configuración de esa cláusula ius fundamentale simile instrumental al efecto de salvaguardar el principio democrático nacional, la caracterización incondicional de la entonces programada UEM como una comunidad de estabilidad) con algunos renglones torcidos (así, en particular, a propósito de su expresa reversión de la doctrina Eurocontrol, afirmando la inmediata proyección paramétrica al DUE de sus estándares iusfundamentales, algo que, en lo

32 Y, partiendo de la Sentencia, Sala 2a, de 12 de octubre de 1993, Maastricht, en BVerfGE 89, 155 y ss., en una amplia serie de resoluciones que no es preciso reiterar en esta nota (véanse, entre otras muchas, la Sentencia TCFA, Sala 2. a de 30 de julio de 2019, as. 2 BvR 1685/14, y 2 BvR 2631/14, como ejemplo de interpretaciones condicionadas de conformidad, previas a la definitiva aceleración y tropiezos que caracterizan la fase previa al cambio de presidencia en la Sala). 
sucesivo, formalmente, ya no se volvería a repetir, sino de un modo distinto, al amparo de la cláusula de identidad constitucional).

En su jurisprudencia de entre siglos, esos parámetros de control se afirmaron y, sin perjuicio de acomodaciones relativamente consecuentes (véase VP de Landau, al amparo de una lectura de la doctrina apuntada en la STCFA Lisboa, que la mayoría acotara en un sentido menos intenso en la STCFA Honeywell), se configuraron de modo vigoroso, sumando al control de ultra vires una complementaria y comprensiva vía de control de aplicabilidad, al margen de la existencia probada de una base jurídica de atribución de competencias y de la acreditada observancia de los principios de subsidiariedad y proporcionalidad que rigen su ejercicio, la vía del control de identidad, ya desde su articulación en la muy relevante sentencia Lisboa. En esa densa decisión, avanzaría ya la Sala 2. en la reivindicación de una jurisdicción de control de aplicabilidad del DUE, mediante una compleja hilazón de intangibilidades, nucleares ( $y$, a medida que se fue poniendo en práctica, también por conexidad), limitativas de un legislador de la integración, materialmente acotado y funcionalmente articulado, como parte de unas previsiones relativas a la acción exterior que, en todo caso, quedarían sujetas a las exigencias del principio democrático. Una comprensiva cláusula que, en último término, ad intra se corresponde con la remanencia de un cualitativo quantum expresivo de esa soberanía nacional que, al hilo del proceso de integración, la representación parlamentaria del pueblo soberano sería responsable de salvaguardar.

De modo que, a mayor avance en el tracto de la integración europea, mayor responsabilidad habían de asumir los órganos constitucionales (en particular, la Dieta y el Gobierno federales) y más acuciante devino para la Sala 2. ${ }^{a}$ la operativa necesidad de reactivar una jurisdicción de control de aplicabilidad, con ocasión del ejercicio de su jurisdicción, en los diversos procedimientos, y, en todo caso, por la disponibilidad que facilita la flexibilización de su régimen de legitimación, en el marco del recurso de queja por inconstitucionalidad; mediante una activación de la ciudadanía en demanda de salvaguarda de la democracia (nacional) que - como ya he dicho en alguna otra ocasión - ha insertado de soslayo en el sistema trazas inequívocas de un populismo jurisdiccional que no se cohonesta con la LF, ni guarda correspondencia alguna con la ley procesal ${ }^{33}$.

33 A propósito de su pretendida función compensatoria en defensa de la democracia, véase, en su faceta doctrinal, la contribución de Huber (2018), que habla, literalmente, de «específica función democrática de ventilación o compensación» (n. ${ }^{\circ}$ marg. $352)$. 
De la identidad como parámetro de (indirecto) control de aplicabilidad del DUE ha resultado, ocasionalmente, una reafirmación de la incondicionalidad de contenidos iusfundamentales (así, en particular, en la singular sentencia Haftbefehl II, 2015). Pero lo cierto es que, de modo recurrente, lo que se plantea es una multifacética reafirmación de la democracia, como una especie de mixtura de derecho y principio fundamental, y (contra lo que se apuntara en Solange I) ya no como expectativa de confirmación pendiente o en proceso, en el seno de la planta institucional de la Unión, sino como una condicionalidad constitutiva de Alemania, en cuanto que miembro de una unión de Estados, lejos, pues, de la condición de mero elemento federado, mediante una cerrada interpretación de la cláusula de intangibilidad que, ex art. 79.3, LF, alcanzaría a configurar un quantum de cualidad estatal, de la que el llamado «legislador de la integración» ni podría disponer ni podría permitir o tolerar que se dispusiera.

Así expuesto, ese criterio hermenéutico constitucional difícilmente podría llegar a casar con la (pendiente) interpretación por parte del TJUE de esa especie de cláusula de garantía institucional de estatalidad que sin duda alguna se quiso salvaguardar mediante el art. 4.2 TUE. Pues lo cierto es que, en su reciente jurisprudencia iuseuropea, la Sala $2 .^{\text {a }}$ del TCFA ha venido insistiendo, de modo persistente, en un sentido difícil de conciliar con los rasgos configuradores de la divisoria, orgánica, competencial y funcional, entre la UE y sus Estados miembros, que esa cláusula convencional presume y demanda.

En todo caso, entre sostener, in genere, la existencia de un núcleo irreductible, si se ha de salvaguardar la existencia de un orden constitucional democrático, y la puntillosa inferencia de facetas y conexidades en una deriva hermenéutica próxima a confundir identidad nuclear e identidad sin más, hay

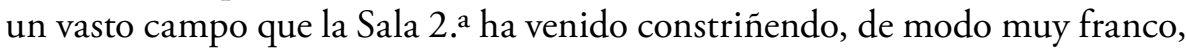
ya desde su referida sentencia Haftbefehl II.

Y otro tanto hay que decir si se trata de la hipótesis de un control de ultra vires. Pues, entre su invocación en supuestos de alejamiento manifiesto y significativo de la divisoria competencial y su puesta en práctica en supuestos de controvertida interpretación (así, por ejemplo, en el ya referido asunto Honeywell) se advierte una cesura. Y más distantes de la concepción originaria están aún otros supuestos más recientes, como Weiss (una decisión extremosa que aterriza, sin frenos, en una pista balizada pro futuro en Gauweiler/OMT); $y$, de otro modo, no poco estrepitoso, de pretendido asiento en su corpus doctrinal, una previa decisión, de 13 de febrero de 2020, TPU, que sobre su apariencia de continuidad realmente aterriza en una pista bacheada sin atender 
a las instrucciones de la torre de control (en este caso, el criterio fundado que sostiene el VP discrepante formulado a esa sentencia de la Sala 2.a).

El último lustro de la jurisprudencia iuseuropea de la Sala 2. ${ }^{\text {a }}$ del TCFA se ha caracterizado, en suma, por una intensificación desmedida de su jurisdicción de control de aplicabilidad del DUE, en un ejercicio de paulatina banalización del principio democrático que, en la sentencia Weiss, ha llegado a su punto álgido.

Que a estas alturas, pese a la discrepante llamada a la morigeración doctrinal y a la modulación de los efectos de su inflamado conceptismo por parte de una alternativa minoría de jueces del interior de la Sala 2. a (mediante VP discrepante a la sentencia de 13 de febrero de 2020), coincidiendo con las primeras manifestaciones de lo que luego fuera la primera oleada de la pandemia y en abierto contraste con la ya conocida reformulación hermenéutica del modo de considerar el encuadramiento iuseuropeo de su jurisdicción de control, por parte de la Sala $1{ }^{\text {a34 }}$, la Sala 2. a, de presidencia saliente, siguiera empeñada en ahondar en una desviación doctrinal, de imposible encaje iuseuropeo y muy dudoso sustento constitucional, tiene difícil explicación racional.

Llegados a este punto, encajada en un callejón sin salida, a la Sala $2 .^{\text {a }}$ de presidencia entrante se le planteaba, de entrada, una ineludible alternativa con las dos opciones siguientes: o bien, caso de querer persistir en la generada situación de conflicto iuseuropeo y de incongruencia constitucional, exponerse a un enfrentamiento saldable mediante el planteamiento de un recurso por incumplimiento contra la RFA, y un llamamiento del Plenario del TCFA para tratar de cohonestar las encontradas aproximaciones de sus dos salas, o bien, en el caso de que se tratara de retornar a la normalización de una relación (jurisdiccional) desquiciada, tratar de recomponer la situación mediante relectura, de conformidad con la complementaria ortodoxia constitucional e iuseuropea, del sentido y alcance del fundamento constitucional de la integración $y$, en consecuencia, de unos controles que, con ser expresivos de su reserva de jurisdicción, quedasen ya constreñidos al terreno siempre equívoco, pero consensuable, de los límites a la integración (se invoque la identidad constitucional o solo un estándar iusfundamental esencial o se denuncie una actuación ultra vires).

Pero, en fin, antes de pasar a concluir nada sobre las alternativas mencionadas (IV), es conveniente repasar lo que se ha dicho y, sobre todo, el modo en que ello se haya dicho en la mayoritaria decisión (de ponencia huberiana)

34 En esa línea pueden entenderse las modulaciones interpretativas de la Sala 1. a , en sus sentencias de 6 de noviembre de 2019, derecho al olvido Iy II (as. 1 BvR 16/13 y 1 BvR 276/17, respectivamente); véase, entre otros, Kühling (2020: 275 y ss.). 
que integra la sentencia Weiss. Lo que es tanto como decir que, antes de concluir nada, lo que procede es tratar de desentrañar las claves del disentimiento con la interpretación prejudicial solicitada al TJUE, de la Sala 2.a de saliente presidencia.

\section{3. ... ¡HASTA DISPARATAR, SIN MEDIDA!}

a. De las tribulaciones de la (vieja) Sala $2 .^{a}$ en (febrero y) mayo de 2020...

En el primer semestre de 2020, en la sentencia de 13 de febrero, primero, y, pocas semanas más tarde, ya mediante su sentencia Weiss, la Sala 2. a de presidencia saliente se ha precipitado por una pendiente, superando previas modulaciones y condicionamientos hermenéuticos (OMT) y haciendo, además, oídos sordos a las ponderadas razones expuestas pocos meses antes por la Sala 1. a , hasta disparatar sin medida. Reconociendo a la interpretación prejudicial del TJUE solo un carácter presuntivo que, en el desempeño de su función de control de identidad o de ultra vires, le cabría soslayar siempre que, en su criterio, no se hubiese atenido el TJUE a su mandato jurisdiccional.

En el caso, ello se traduce en la expresa negativa a que se aplique en Alemania una interpretación prejudicial que se considera incomprensible y objetivamente arbitraria, por haberse dictado sin sujeción al mandato que, ex art. 19.1, 2. ${ }^{\text {a }}$ frase, TUE, en relación con la ley de autorización, se le atribuye; contraviniendo el estándar de legitimación democrática que, ex art. 23.1, 2. a frase, en relación con los arts. 20.1 y 2 y 79.3 de la LF, incondicionalmente le cumple asegurar ${ }^{35}$. Un aserto en el que insiste la Sala, cuestionando una deferencia del TJUE que habría supuesto —en su opinión - una falta de control jurisdiccional efectivo de la discrecionalidad del $\mathrm{BCE}$ y, con ello, una desatención del principio basilar de atribución concreta y limitada de competencias, de facto invalidado, y, en consecuencia, también una quiebra del principio democrático que lo sustenta y alumbra ${ }^{36}$.

En el intento de reforzar esa ligazón entre una concreta y limitada atribución de competencias y el principio democrático (nacional), la Sala ensaya una novedosa caracterización dogmática del principio de proporcionalidad, como principio relativo a la determinación de las bases jurídicas (atributivas de competencia) antes de proceder a su proyección, germánico modo, al examen (sustitutivo del realizado por el TJUE) del programa de compra de bonos ${ }^{37}$.

\footnotetext{
35 Vid. n. ${ }^{\mathrm{o}}$ marg. 112 y 118.

36 Vid. sus directrices $3 .^{\mathrm{a}}, 4 .^{\mathrm{a}}$ y $5 .^{\mathrm{a}}$ (n. ${ }^{\mathrm{o}}$ marg. 142,156 y 158).

37 Vid. n. ${ }^{\circ}$ marg. 139, 158, 165.
} 
Y, finalmente, tras negar que la pretendida vulneración de la interdicción de financiamiento monetario o la supuesta afectación de la responsabilidad presupuestaria de la Dieta federal fuesen algo más que una lucubración hipotética $^{38}$, se impuso al Gobierno y a la Dieta federales que, en cumplimiento de su responsabilidad por la integración, se asegurasen de que el BCE se hubiese atenido antes y se atuviera después a las exigencias derivadas de ese (reformulado) principio de proporcionalidad, en la procura de acomodar la actuación del $\mathrm{BCE}$ al Tratado, concluyendo que ninguno de «los órganos constitucionales, autoridades y tribunales (lo que alcanza al Banco federal)» podría participar en «la creación, aplicación, ejecución y operacionalización de actos ultra vires»"

Pues bien, al tratar de valorar la proyección al caso de semejante aporte doctrinal se advierte la hipertrofia de una arrogada jurisdicción de control de ultra vires, expresiva de una irresponsabilidad por la integración de la Sala 2.a, que, de modo acelerado, en el primer semestre de 2020, se ha movido a contramano de la Sala $1 .^{\mathrm{a}}$, sin cambiar el paso, empeñada en un distorsionado argumentario, mediante una extrapolada amalgama de criterios, procesales y sustantivos, de penosa aplicación al caso.

\section{b. ... a la práctica de un control de ultra vires de imposible encaje iuseuropeo y muy dudoso anclaje constitucional}

En el caso Weiss se puede apreciar, en efecto, que la Sala ha maleado un control, problemático en sí mismo, hasta la distorsión de la constitutiva divisoria funcional y ordinamental en que se sustenta la Unión, estirando la aplicación de sus tópicos, banalizados, en una línea de pretendida reformulación, ya previamente avanzada.

Se habla aquí de banalización de sus tópicos, porque de la fundada exigencia argumental de extraordinaria y significativa alteración del orden competencial, que se presume autorizado mediante la ley de prestación del consentimiento respecto de un determinable programa de integración, en la sentencia Weiss se pasa a la asertiva descalificación de una interpretación del TJUE de la que se discrepa. Dando así un paso más en su empeño de reformular un control de aplicabilidad del DUE que, apenas tres meses antes, con la oposición de una minoría de tres jueces, se había empeñado la mayoría de la Sala en hacer extensivo a su decisión de enmendar el procedimiento de autorización parlamentaria por mayoría no cualificada de la atribución de funciones

38 Vid. n. ${ }^{\circ}$ marg. 217 y 227 , respectivamente.

39 Vid. n. ${ }^{\circ}$ marg. 232 y 234. 
jurisdiccionales al denominado tribunal (de apelación) en el marco del Acuerdo sobre la patente única europea, mediante un novedoso «control formal de la transferencia», como pretendida modalidad del control de ultra vires ${ }^{40}$.

Y, de ese modo, por insistencia y acumulación, la Sala 2. a de presidencia saliente se desliza por la resbaladiza pendiente de su autoconfiguración como una especie de permanente, aunque discontinua y subsidiaria, instancia jurisdiccional de control de (alternativa) legalidad de (al menos, en potencia) la práctica totalidad de los pasos del sucesivo tracto de la integración (en un vasto sentido, puesto que, más allá del proceso de configuración de la UE, se pretende proyectar a lo que se denomina otros procesos análogos o asimilados, tal y como se sostiene en la antecedente sentencia de 13 de febrero de 2020). $Y$ con un estilo asertivo y apodíctico que causa perplejidad, pese a que se reconozca que, como a toda otra jurisdicción, al TJUE también se le habría de tolerar siempre cierto margen de error, la Sala 2. a afirma, rotundamente, que el TJUE ha dado a sus cuestiones prejudiciales una respuesta insuficiente y, en todo caso, objetivamente arbitraria y alejada de principios metodológicos reconocidos.

Lo disparatado de semejante deriva de unilateralidad ha topado con la crítica doctrinal en sede académica y, lo que es más relevante, pensando en su pronta reversión, dentro de la propia Sala 2.a, por más que en Weiss no se reflejara ello de manera expresa en un voto particular.

Ha sorprendido a propios y extraños el grosor (por lo grueso y por lo grosero) de la descalificación de la autorizada interpretación prejudicial del TJUE. Y ha sorprendido, en particular, el ensayo doctrinal que, como si fuese incontestable o de suyo evidente, la Sala 2. ${ }^{a}$ (de presidencia saliente) blande a propósito de la interpretación del sentido y alcance de la proporcionalidad. Concebida ahora por la Sala no como un principio relativo al ejercicio de las competencias, sino como uno relativo a la base jurídica de su atribución; en este caso, como un principio relativo a la divisoria entre la competencia en materia económica (complementaria de la remanente competencia de los EE. MM.) y la competencia en materia monetaria (exclusiva) del BCE.

40 En la referida sentencia sobre el tribunal único de patentes, en síntesis, la mayoría de

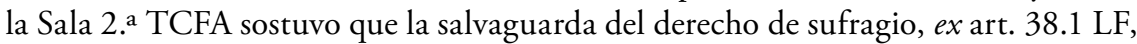
alcanzaba también al cumplimiento de los requisitos para la realización de una transferencia efectiva de derechos soberanos, ex art. 23.1 LF; y, por ello, los ciudadanos tendrían un derecho fundamental a que la transferencia de derechos soberanos solo se produzca en las formas previstas por la LF, en la $2 .^{\mathrm{a}}$ y $3 .^{\mathrm{a}}$ frases del art. $23.1 \mathrm{LF}$ y en el art. 79.2 LF (directriz 1.a). 
Y lo más sorprendente es que, sin solución de continuidad, no habiendo sido ese el criterio sostenido en Luxemburgo, se diga que la Gran Sala del TJUE habría tergiversado, en su interpretación, el DUE. Denunciando su insuficiencia de jurisdicción al asumir sin cuestionar los objetivos pretendidamente perseguidos por el BCE y por el desfalleciente test de proporcionalidad aplicado, sin ponderar los diversos intereses en conflicto y de modo menos intenso que en otros ámbitos materiales. Se rechaza, en consecuencia, no solo el resultado — acaso criticable-, sino también —y sobre todo- el método seguido por el TJUE, un método ajeno a los conocidos — afirma tajante la Sala 2. ${ }^{\mathrm{a}}$ -

Pues bien, si se reformulan esas afirmaciones, lo que está diciendo la Sala $2 .^{a}$ es que el TJUE, al operar con el criterio asentado y ampliamente compartido, y no con su novedosa reformulación, habría incurrido en la arbitrariedad de sentar un juicio con base metodológica desconocida. Que eso es algo disparatado no está en discusión. En duda podría estar, en cambio, la oportunidad o pertinencia de avanzar en la concepción de la proporcionalidad como un principio en el sentido que defiende aquí la Sala 2. ${ }^{a}$ (es decir, no solo como un principio relativo a la modulación del ejercicio de las competencias, sino también, porque así se salvaguardaría mejor, como un principio instrumental a la atribución concreta y limitada de competencia y, en consecuencia, al principio democrático de base).

Pero, pensando en esa eventual tarea doctrinal, es preciso aclarar que ese novedoso enfoque Weiss a propósito del sentido y alcance del principio de proporcionalidad, ex art. 5.1 y 4 TFUE, no solo contraría la interpretación del TJUE y, al hilo del crítico acompańamiento de su jurisprudencia, el estado generalizado de la cuestión en la doctrina iuseuropea, sino que choca también con la asentada concepción de la proporcionalidad que opera dentro del orden constitucional alemán cuando de la divisoria competencial entre la Federación y los Länder se trata ${ }^{41}$. Sin que el hecho de que lo federal sea solo una parte de la amalgamada suma de elementos característicos de la Unión suponga, a esos efectos, inconveniente doctrinal o impedimento racional alguno para su debate.

Por lo demás, ante una aproximación al principio de proporcionalidad como la que, frente a la expuesta por el TJUE, contraoferta la Sala 2. (de saliente presidencia), es oportuno recordar la diferencia conceptual que media entre el supuesto de adopción de una medida desproporcionada, pero que haya sido dictada invocando el correspondiente título (expreso o implícito) atributivo de competencia con soporte en una determinada (concreta o finalista) base

$41 \quad$ En ese sentido, por otros muchos, vid. Wendel (2020: 979 y ss.). 
jurídica, y la actuación o adopción de medidas carentes de base competencial alguna. Pues, de lo contrario, no habría modo seguro de saber cuándo se trata de un supuesto de actuación sin base alguna, al margen de las atribuciones competenciales, y cuándo se está ante un caso de actuación ilegal ${ }^{42}$.

Y quizá sea esa confusión conceptual de fondo, lo que mejor explique la atribulada deriva en la concepción y aplicación del control de ultra vires, por la que la Sala 2. ${ }^{a}$ de presidencia saliente se ha visto arrastrada al final ya de su mandato, en el primer semestre de 2020. Y así, a medida que se esforzaba por alumbrar una nueva faceta de control formal sobre el procedimiento de autorización, antes de decidirse a cuestionar la interpretación del TJUE, en el caso Weiss, la Sala 2. ${ }^{\text {a }}$ iba transmutando su asentado control de ultra vires (a la vista de un programa de integración, delimitable, democráticamente autorizado) en un mero y rutinario - por su recurrencia y alcance inusitado- control de legalidad (por hipótesis) de cualesquiera actuaciones ${ }^{43}$.

Pues bien, advertida esa desorientación conceptual, intensificada ya finalizando el mandato presidencial de la Sala 2. a antes que lanzarse a la prefiguración doctrinal de una jurisdicción de conflictos, iusinternacional o de composición mixta, al efecto de resolver situaciones de manifiesta disidencia jurisdiccional como la que se ha puesto de manifiesto en Weiss/PSPP, se imponía un ejercicio de serena reflexión, al hilo de su renovación presidencial. Al efecto, la Sala 2. ${ }^{a}$, de presidencia renovada, pensando en soltar de inmediato el lastre de Weiss, contaba ya con el renovado planteamiento, en la Sala 1. a , de la divisoria jurisdiccional, no ahondando en el activismo, sino mediante su activación como jurisdicción iuseuropea. Pensando, en todo caso, en recuperar el rigor técnico perdido en la fundamentación de su jurisprudencia iuseuropea más reciente. Y, en lo posible, retomando ese empeño cooperativo sin el que apenas es concebible la práctica de la jurisdicción del DUE y que, sin perjuicio de la centralidad del TJUE, de soslayo, alcanza también a los correspondientes tribunales constitucionales (o/y supremos) de los Estados miembros y a esa jurisdicción de garantía de mínimos comunes que encarna el TEDH.

42 Vid. Wendel, ibid., que, como yo mismo, en este punto, remite a la precisión conceptual de Nettesheim (2003: 389 y 408-409).

43 En esa desviación se funda, en lo sustancial, el VP discrepante a la referida Sentencia de la Sala 2. ${ }^{\text {, }}$, de 13 de febrero de 2020. 


\section{A MODO DE CONCLUSIÓN, O SOBRE CÓMO RECUPERAR EL SENTIDO DE LA MARCHA, SIN PERJUICIO DE UNA REMANENTE RESERVA DE JURISDICCIÓN DE (HIPOTÉTICO) CONTROL DE LÍMITES A LA APLICABILIDAD DEL DUE}

La retorsión culterana del conceptismo ínsito en los tópicos expresivos de su arrogada jurisdicción de control de aplicabilidad del DUE, que culmina el cierre de la presidencia Vosskuhle, mediante el cuestionamiento de la autorizada interpretación del TJUE en el asunto Weiss y la imposición de un plazo perentorio (de tres meses) a los órganos constitucionales, responsables por la integración, para que verificasen si, en su aplicación del programa PSPP, el BCE atendió o no al principio de proporcionalidad (lo que de modo indirecto, mediante la transmisión de la correspondiente documentación por parte del BCE al Banco Federal $-\mathrm{BuBa}$-, finalmente, la Dieta federal alcanzaría a verificar $)^{44}$, ha dejado a la Sala $2^{a}$., de renovada presidencia - que no al TCFA (que, pese al viraje doctrinal de la Sala $1 .{ }^{a^{45}}$, como tal no habría llegado a intervenir) — en una situación particularmente excéntrica.

Pero, acaso por lo extremoso de la dislocación doctrinal que se dejaba como legado, a mediados de 2020 , a la Sala $2 .^{a}$ de presidencia renovada le venía dada la oportunidad de actuar sin demora (si es que no se quería propiciar la intervención sancionatoria del TJUE, en incumplimiento, o/y una corrección plenaria por parte del TCFA) para dar un golpe de timón rectificando esa deriva.

O, dicho de otro modo, que de la Sala $2 .^{\text {a }}$ de renovada presidencia (König) cabía esperar que no demorase la decisión de lidiar, parando,

$44 \mathrm{Al}$ efecto de formar criterio, ante la prescripción de una tarea de verificación del soporte decisorio de las actuaciones del BCE en el marco de su programa PSPP, la Dieta federal escucharía a la academia, expresamente llamada a informar (respecto de las intervenciones de Christian Callies, Marcel Fratzscher, Martin Höpner, Franz C. Mayer, Dirk Meyer, Jörg Rocholl, Christian Walter und Bernhard W. Wegener; puede consultarse el sitio de la Dieta federal en www.bundestag.de).

45 Más reciente es la decisión de reafirmar la aplicación ad extra del estándar de tutela de derechos fundamentales al poder público alemán, sin perjuicio de modulaciones, ex art. 1.3 LF, en relación con la prestación de tutela, fuera del territorio nacional, ex arts. 10.1 y 51.1, 2. a , LF, como derechos de defensa, frente a sus actuaciones de vigilancia y monitoreo de telecomunicaciones a extranjeros (vid. la Sentencia, de 19 de mayo de 2020, as. 1 BvR 2835/17, en la que, constatada esa vulneración, se deja al legislador un plazo de adaptación de la normativa declarada inconstitucional, hasta el 31 de diciembre de 2021, para que se dicte una nueva regulación, conforme a la LF -n. ${ }^{\circ}$ marg. 331-). 
mandando y templando la embestida, esa desbocada jurisdicción de control de la aplicabilidad en Alemania del DUE es algo que ya podía intuirse a la vista del mencionado voto discrepante que tres de sus magistrados de incorporación más reciente opusieron, de modo fundado (guiados de un manifiesto empeño de contraste de la doctrina allí sentada con los tópicos de su jurisprudencia iuseuropea), a la extremosa configuración de una faceta formal o procedimental del control de ultra vires, pretendidamente consecuente con su previa trayectoria doctrinal/conceptista.

La puntillosa relación de los sucesivos pasos por los que se ha configurado, así como el control de identidad, el control de ultra vires, llevó en esa ocasión a los tres discrepantes a negar que esa faceta formal pretendidamente instrumental al principio - ius fundamentale simile de democracia que la mayoría había querido articular como un corolario más del control de ultra vires - se acomodase al sentido último de la cláusula de apertura a la integración europea, ex art. 23.1 LF; antes al contrario, de la extensiva interpretación de la Sala 2. a resulta el constreńimiento de su tenor y su solapamiento, además, con el residual fundamento de apertura que subsiste en el art. 24.1 LF.

Los discrepantes vieron, en ese proceder (como ya se viera en $O M T$ ), una vía de restricción adicional del despliegue democrático de la Dieta federal en el condicionamiento indirecto de su discrecionalidad relativa a la hora de adoptar unas u otras mayorías, en atención al carácter y al alcance de sucesivos avances, incluso menores, o relativos a aperturas conexas o propias de otros procesos análogos o similares, al proceso de configuración de la UE, como era el caso con el tribunal (de apelación) de patente única europea. Una interpretación apta al efecto de generar incertidumbre en la Dieta federal, al dudar si actuar siempre y en todos los casos como si realmente fuese necesaria una mayoría cualificada de reforma de $2 / 3$ (tal y como la Sala 2. a dejaba sentado al plantear que en toda hipótesis de apertura concurriría esa nota de trascendencia que se precisa para dejar de lado una mayoría ordinaria).

De ese modo, la pretendida función tuitiva del amparo constitucional al efecto de salvaguardar la democracia se transmutaba, de facto, como bien se advierte ya en ese voto discrepante, en una vía expedita al populismo procesal por la que del control de ultra vires resulta no una garantía de democracia, sino una modalidad imprevista de extensivo control de legalidad de actuaciones parlamentarias ordinarias, en las que no necesariamente se arriesga ese remanente cuantitativo y cualitativo de competencias que en la jurisprudencia iuseuropea de entre siglos, in genere o sub specie autonomía presupuestaria, se anuda a la democracia/soberanía de Alemania.

La decidida oposición de los tres discrepantes a semejante distorsión del ultra vires les llevaría a negar, en esa decisión de febrero de 2020, con un 
puntilloso apoyo en la antecedente doctrina de la Sala 2. a , que realmente se tratase de un supuesto propio de esa modalidad de control. Posteriormente, pese al silente repliegue de discrepancia (como contrapartida, acaso, tras la modulación dentro del colegio senatorial que condujo a la formulación del singular emplazamiento a la Dieta federal para que se verificase la actuación seguida por el BCE y la genérica admonición a la responsable actuación de todos los órganos constitucionales, tribunales y autoridades), la Sala 2. a adoptó su sentencia Weiss por mayoría de siete votos contra uno, innominado (pero que, por lo que después se ha visto, no es muy arriesgado presumir que fuera cosa de quien, de inmediato, vino a hacerse con el liderazgo de la Sala 2. König).

En ese sentido, apunta una inmediata decisión de inadmisión, de 15 de junio de 2020, en formación de tres jueces, que, aun en presencia del ponente responsable inmediato, como redactor y autor, de Weiss, y en supuesto de aplicación de doctrina ${ }^{46}$, sin perjuicio del mantenimiento de los tópicos de su jurisprudencia iuseuropea, anunciaba el esperado viraje doctrinal, apuntando a la reconsideración de la deriva procesal-populista en supuestos de rogación de control de identidad o de ultra vires, en queja por inconstitucionalidad ${ }^{47}$.

En el Auto de 15 de junio de 2020 (asuntos 2 BvR 71/20 y 72/20), dictado por la Sección de la Sala 2. ${ }^{\mathrm{a}}$ integrada por su actual presidenta, se declara, en efecto, que, aun si el programa CSPP (Corporate Sector Purchase Programme) no cumpliera las exigencias impuestas por el derecho primario, los recursos de queja por inconstitucionalidad que se dirigen contra este y contra las consecuentes decisiones del BCE se habrían de considerar inadmisibles por inobservancia de los requisitos de fundamentación que establece el TCFA al efecto de interponer recursos de ultra vires o de identidad ${ }^{48}$.

46 Vid. en BVerfGE 142, 123 y ss., n. ${ }^{\circ}$ mar. 97; STCFA, de 30 de julio de 2019, as. 2 BvR 1685/14 y 2 BvR 2631/14, n. ${ }^{\circ}$ marg. 93.

47 A propósito, la caracterización de los casos recurrentes de querulancia soberanista como supuestos expresivos de una especie de compensación democrática — plebiscitaria simile, si vale la licencia-, auxiliares necesarios, al efecto de que el TCFA $(v$. gr., la Sala 2.a) tuviera siempre la ocasión de examinar los pasos que la Dieta federal (y los demás órganos constitucionales) fueran dando, o dejando de dar, en el tracto continuo de la integración (vid. Huber, loc. cit. en nota 33).

48 En esta ocasión (en C.I.2.a), se subraya que para recurrir en amparo constitucional en las vías de control de identidad o ultra vires «se requiere una presentación suficientemente justificada» (vid. BVerfGE 140, 317 y ss., n. ${ }^{\circ}$ marg. 50; E 142, 123 y ss., n. ${ }^{\circ}$ marg. 83; STCFA, de 30 julio 2019, cit., n. ${ }^{\circ}$ marg. 95-6 y 107-8). 
Parecía prefigurarse, así, el esperado cambio de interpretación de la legitimación soberanista en amparo constitucional, pues, aun sin llegar a excluirse que el CSPP pudiera llegar a incidir en el ámbito de la política económica ${ }^{49}$, se subrayaba la insuficiencia de fundamentación de unos recursos de queja por inconstitucionalidad que ni acreditaban la vulneración del art. 127 TFUE ni aclaraban tampoco si se había de aplicar al caso el art. 107.1 TFUE, antes de concluir que ni se sostenía la existencia de esa significativa quiebra estructural de la divisoria competencial de la Unión que aducían los recurrentes ni se fundamentaba tampoco el denunciado favorecimiento selectivo a unas determinadas empresas ${ }^{50}$.

En lo que parecía ser ya el bosquejo de una reconsideración de la disciplina procesal a propósito de alegato (recurrente) mixto de (pretendida) vulneración del derecho ius fundamentale simile ex art. 38.1, 1. a frase, LF, en relación con el principio de soberanía popular, ex art. 20.1 LF, en el referido auto de la Sala 2. ${ }^{a}$, se enfatizaba que, para la admisión a trámite de una queja de ultra vires, se había de acreditar suficientemente un supuesto de incumplimiento de la competencia, evidente y de alcance estructural; un desbordamiento manifiesto de las competencias atribuidas, que no pudiera justificarse mediante la aplicación de normas metodológicas generales. Al efecto de clarificar la situación, se afirma que esa suficiencia puede presumirse cuando la transgresión de la competencia tenga un peso considerable y pueda socavar el principio de atribución limitada (porque siendo equivalente a una reforma o evolutiva compleción del derecho primario no hubiese contado con la precisa intervención autorizante del «legislador de la integración», ex art. 23.1, 2. a frase, LF, o conforme a lo dispuesto en la ley de responsabilidad por la integración ${ }^{51}$.

49 Así, en particular, si la adquisición de bonos corporativos por parte del Eurosistema en el marco del CSPP constituyera una ayuda — vid. en C.I.2.b—, en forma de subvenciones o en su variante de alivio de cargas, estableciendo como criterios limitadores la observancia de la libre competencia y de los DD. FF. — vid. en C.I.2.b) bb)-.

50 Ibid., en C.I.2.c), in fine.

51 Vid. C.I.2.a; y, en esa línea de pretendida aplicación de doctrina previa, a propósito de la admisión a trámite de control de identidad, se recuerda que se ha de exponer de forma razonada y fundamentada que los órganos constitucionales no han cumplido su responsabilidad por la integración porque no enfrenten la afectación, mediante las medidas adoptadas por las instituciones... de la UE, de intangibles, ex art. 79.3 LF, en relación con art. 23.1, 3. ${ }^{\text {a }}$ frase, LF (C.I.2, a in fine); así, en particular, si afectasen a la potestad del BTag, porque no observasen su responsabilidad general en materia de política presupuestaria o porque el poder público de la UE se desplegase de modo inconsecuente con los principios democráticos salvaguardados ex art. 79.3 LF (vid. 
Y tras esa inmediata prefiguración de una depurada reafirmación de los tópicos expresivos de su reserva de jurisdicción de control de (indirecta) aplicabilidad del DUE, avanzada desde una de sus secciones, se lanza ya la Sala 2. a a la reformulación de su propia responsabilidad por la integración. Partiendo de esa ajustada, por restricta, reconsideración del papel procesal auxiliar del querulante alícuota soberano, en una línea de confluencia doctrinal con la Sala 1. a , mediante la formal asunción paramétrica de la Carta de DD. FF. de la UE. Ensayando, así, su reubicación en el comprensivo marco de la unión jurisdiccional en la UE o, como yo prefiero decir, de la jurisdicción del DUE; como una efectiva instancia de salvaguarda de los estándares constitucionales propios y de los estándares comunes al conjunto (de los sujetos al derecho) de la Unión.

Esto no se ha de confundir con una especie de renuncia a sus tópicos de control, puesto que tal cosa no se ha producido, ni, en atención a su matizada reiteración por parte de la Sala $2 .^{\text {a }}$ de renovada presidencia, es previsible que se vaya a producir.

Ahora bien, lo que sí se advierte, finalizando ya el fatídico 2020, es que la Sala, mandando y templando, como requiere siempre una canónica lidia, de una parte, trata de preservar el empleo, ocasional, ya no trivializado, de sus controles de identidad y ultra vires (al efecto de salvaguardar, frente a la pretendida aplicabilidad del DUE, no otros aspectos conexos o adicionales, pero sí los contenidos constitucionales nucleares que delimitan el margen de discrecionalidad del que se sigue caracterizando de «legislador de la integración»). Y, de otra parte, ha procedido a reformular su posición de garante de los derechos fundamentales en el espacio constitucional que le compete, pero ya no (como, de uno u otro modo, muestra su jurisprudencia iuseuropea de los últimos cinco o seis años) de un modo elusivo o renuente (en el que sigue, a su modo, también el TC español), sino mediante la consecuente asunción paramétrica de la Carta de DD. FF. de la Unión, en un diverso grado, según que se trate de supuestos de una plena o solo de una relativa sujeción al DUE. Asumiendo, así, las claves de una jurisprudencia del TJUE tanto más segura cuanto más se avance en la ajustada plasmación de los principios y estándares iusfundamentales de la Carta (lo que, sin que se formule ello abiertamente, parece reconectar el acendrado acervo de sus modalidades de control de aplicabilidad del DUE a la lógica inmanente de su originaria aproximación Solange, y, si así fuese, al repliegue de su jurisdicción al efecto de una residual práctica del control de los límites).

Sentencia de Sala 2. a de 30 de julio de 2019, cit., n. ${ }^{\mathrm{o}}$ marg. 155; y Sentencia de Sala 2..$^{\text {, de }} 5$ de mayo 2020, Weiss, n. ${ }^{\circ}$ marg. 227 y 228). 
Y así, mediante sentencia de 1 de diciembre de 2020, se afirma que, en las hipótesis de plena predeterminación normativa iuseuropea de la actuación estatal, los DD. FF. de la LF no constituyen ya el inmediato parámetro de control de su aplicación en Alemania, pasando a ser decisivos a ese respecto los DD. FF. de la Unión (prestando la debida atención a la Carta de DD. FF. de la $\mathrm{UE}^{52}$, tanto a la luz de su interpretación por parte del TEDH como a su configuración como derechos fundamentales comunes a las tradiciones constitucionales, a partir de su interpretación por parte de otros tribunales constitucionales y supremos de los Estados miembros). Y, a propósito de la asunción de esa tarea hermenéutica de aplicación del parámetro iuscomunitario de control, el TCFA se considera inserto ya en un marco cooperativo con el TJUE y con el TEDH y con los demás tribunales constitucionales y supremos de los Estados miembros.

Como se ha apuntado ya, esta reformulación de su función como juez del DUE no lleva, sin embargo, a la Sala 2. a a declarar en suspenso su reserva de jurisdicción de control (en este caso) de identidad. Al contrario, esa reserva se reafirma como garantía eventual de superación de unos límites intangibles, que en el caso no se constatan, dado el grado de solapamiento de tutela que la Sala 2. ${ }^{\mathrm{a}}$ encuentra al poner en relación la garantía iusfundamental asegurada mediante el art. 4 de la Carta y la incondicional exigencia iusfundamental que contiene el art. 1.1 de la LF ${ }^{53}$. Es más, si — como he apuntado ya - se considerase a la luz del sentido prístino de su reserva Solange, este repliegue en el ejercicio de su rogada jurisdicción de control de identidad podría muy bien haberse formulado diciendo "en tanto que" a los contenidos incondicionalmente garantizados por la LF se oponga una tutela equivalente, en lo esencial, mediante la interpretación congruente que se ha dicho del parámetro inmediato de la Carta de DDFF de la UE, la Sala (2.a) no se sentirá “impelida” a ejercitar su jurisdicción (de reserva) al efecto de salvaguarda de la identidad constitucional que, incondicionalmente, se puede llegar a oponer a la aplicabilidad en Alemania del DUE».

52 En esa línea de consideración paramétrica de la Carta, se cuenta ya con la previa trayectoria de otros Tribunales, como el Verfassungsgerichtshof de Austria (vid., a propósito de la decisión relativa a los asuntos U 466/11, e. a., la conferencia de Cruz Villalón, 2017: 5-27 y 29-42), o el Tribunal Constitucional de Bélgica (Sentencia de 1 de marzo de 2018, as. 26/2018, en B.9 y 15 y ss., www.cont-cour.be).

53 El contraste, en este punto, de la sentencia Haftbefehl III con la controvertida sentencia Haftbefehl II resulta particularmente ilustrativo de la renovada aproximación, procesal y sustantiva, por parte del TCFA a la interpretación de sus tópicos de control de aplicabilidad del DUE. 
Pues bien, siendo como es notorio que con la renovación presidencial de la Sala $2 .^{\text {a }}$ han llegado una inmediata revisión, de rigor técnico, y el anuncio de cooperativo encuadre funcional de su jurisdicción de control de aplicabilidad del DUE, no es menos evidente que, en lo sustancial, esa reserva de jurisdicción que se arroga el TCFA formalmente se mantiene. Solo que, desde ahora, en adelante, predispuesto a cooperar y en posición proactiva. Se trata, así, de reponer al TCFA, como juez del DUE, en el sitio que había abandonado y a la espera también, por lo que se atisba, de recuperar esa condición de referente que había tenido entre algunos de sus correspondientes de otros EE. MM.

\section{BIBLIOGRAFÍA}

Cruz Villalón, P. (2017). Der Stellenwert der Grundrechte-Charta im europäischen Verfassungsverbund (ed. bilingüe), en la versión revisada que se publica (El valor de posición de la Carta de derechos fundamentales en la comunión constitucional europea), en Teoría y realidad constitucional, núm. 39, 85-101.

— (2020). Exit Karlsruhe. El Pais, 13-5-2020. Disponible en: https://bit.ly/3iAx2a7.

Huber, P. M. (2018). Art. 19, Absatz 4 GG. En H. von Mangoldt, F. Klein y Ch. Starck (eds.). Kommentar zum Grundgesetz: GG. München: C. H. Beck.

Kühling, J. (2020). Das "Recht auf Vergessenswerden" vor dem BVerfG - November(r) evolution für die Grundrchtsarchitektur im Mehrebenensystem. Neue Juristische Wochenschrift, 275.

López Castillo, A. (2017a). Europaei, audi, quid convenit statuitque domina verbum. Revista Española de Derecho Constitucional, 111, 341-378. Disponible en: https://doi. org/10.18042/cepc/redc.111.11

- (2017b). Cuestión prejudicial en segunda ronda. Revista General de Derecho Constitucional, 25.

Lozano Cutanda, B. (2020). La sentencia del tribunal federal alemán, ¿y ahora qué? Disponible en: https://bit.ly/3uOuWWn.

Ludwig, M. (2020). The consequences of the judgment of 5 May 2020, Public Hearing. Disponible en: www.europarl.europa.eu.

Mangas Martín, A. (2020). El Tribunal constitucional alemán y su «fuego amigo» sobre el TJUE y el BCE. Análisis del Real Instituto Elcano, 72.

Mayer, F. C. (2000). Kompetenzüberschreitung und Letztentscheidung: das Maastricht-Urteil des Bundesverfassungsgerichts und die Letztentscheidung über Ultra-vires-Akte in Mehrebenensystemen. München: C. H. Beck.

- (2020). Auf dem Weg zum Richterfaustrecht? Verfassungsblog [blog], 7-5-2020. Disponible en: https://bit.ly/2TDRPyO.

Meier-Beck, P. (2020). Ultra Vires? D’Kart Antitrust [blog], 11-5-2020. Disponible en: https://bit.ly/3uXrk4x. 
Menéndez Menéndez, A. J. (2020). La larga crisis existencial de la Unión Europea. En A. Blanco, A. M. Chueca, J. A. López y S. Mora (coords.). Informe España (pp. 15-90). Madrid: Editorial UPC.

Neruda, P. (1924). Veinte poemas de amor y una canción desesperada. Santiago de Chile: Nascimento.

Nettesheim, M. (2003). Kompetenzen. En A. von Bogdandy y J. Bast (eds.). Europäisches Verfassungsrecht (pp. 389-439). Berlin: Springer Verlag.

- (2020). Das PSPP-Urteil des BverfG: ein Angriff auf die EU? Neue Juristische Wochenschrift-München, 73 (23), 1631.

Rath, Ch. (2020). Der Flucht des guten Rufs. Legal Tribune Online, 2-11-2020.

Rubio Llorente, F. (2013). La Constitución como forma del poder. Madrid: Centro de Estudios Políticos y Constitucionales.

Stein, T. (1986). Richterrecht wie anderswo auch? Der Gerichtshof der Europäischen Gemeinschaften als Integrationsmotor. Karlsruhe: Müller Juristischer Verlag.

Weiler, J. H. H. y Sarmiento Ramírez, D. (2020). The EU Judiciary After Weiss - Proposing a New Mixed Chamber of the Court of Justice. Ejil: Talk! [blog], 8-7-2020 Disponible en: https://bit.ly/3irT0vF.

Wendel, M. (2020): Paradoxes of Ultra-Vires Review: A Critical Review of the PSPP Decision and Its Initial Reception. German Law Review, 21 (5), 979-994. Disponible en: https://doi.org/10.1017/glj.2020.62. 